\title{
Pulmonary Anthrax Caused by Contaminated Sacks
}

\author{
J. B. ENTICKNAP, ${ }^{1}$ N. S. GALBRAITH, ${ }^{2}$ A. J. H. TOMLINSON, ${ }^{3}$ and \\ T. F. ELIAS-JONES ${ }^{4}$ \\ From East Ham Memorial Hospital, London, E.6, ${ }^{\mathrm{i}}$ the Health Department, London Borough of Newham, London, E. $15,{ }^{2}$ \\ the Public Health Laboratory Service, County Hall, London, S.E.r. ${ }^{3}$ and the City Laboratory, Glasgow ${ }^{4}$
}

A 54-year-old Jamaican employed as a grinding machine operator developed pulmonary anthrax and died within two days. In the eight days before his illness he had been grinding sterilized bone charcoal delivered in second-hand sacks, some of which had been used to import the raw bone before its sterilization. Bacillus anthracis was isolated from four out of six sacks examined and is considered to have been the source of the infection.

Pulmonary anthrax is an uncommon disease in Great Britain, only six cases having been reported in the 30 years 1927 to 1956 (Ministry of Labour, 1959). The case described in this paper is the first to be attributed to contaminated sacks.

\section{Case History}

The patient, a Jamaican man aged 54 years, had lived and worked in the East End of London since his arrival in England in 1961.

On July 21 1965, he left work early because of backache. When examined later the same day there was tenderness in the lumbar region but no other physical signs. There were no respiratory symptoms and examination of the chest revealed nothing abnormal. He was treated symptomatically with analgesics. Two days later he began to experience continuous pain in the upper abdomen. This increased in intensity during the afternoon and he was taken by car to his doctor's evening surgery. He was said to be feverish. Whilst sitting in the waiting room he collapsed and died within a few minutes.

At necropsy there were no skin lesions. There was intense oedema of the glottis with superficial ulceration but no membrane was present. The lungs were intensely congested and there had been haemorrhage into their posterior parts. The main air

Received for publication July $26,1967$.

Requests for reprints should be sent to Dr. N. S. Galbraith. Dr. A. J. H. Tomlinson died before this paper was completed. passages contained blood-stained secretions and there were bilateral blood-stained pleural effusions, each of about one litre. The heart was flabby with subendocardial petechiae and a small blood-stained effusion in the pericardium. There were multiple acute ulcers in the antrum of the stomach but no generalized erosion. There was a small haemorrhagic effusion in the peritoneum. The other organs were congested but there was no pre-existing disease.

Histological examination of the lungs revealed an extensive pneumonitis, and numerous black particles and rod-shaped bacilli were seen. Apart from oedema of the larynx and toxic changes in the liver, no other abnormalities were demonstrated. Bacteriological cultures from the blood and lungs yielded a profuse growth of Bacillus anthracis.

\section{Occupational History}

The patient had had no contact at home or at work with materials known to be associated with anthrax; he had worked for three years as a grinding machine operator in a London firm which specialized in the fine grinding and pulverizing of manganese dioxide, graphite, charcoal, and other materials. The only material of animal origin handled by the firm was bone charcoal.

The patient ground over six and half tons of bone charcoal in the eight days before he became ill; of 13 employees engaged in the grinding room of the factory he alone ground this material. Previously he had ground manganese dioxide.

The charcoal was from a batch of ro tons which was delivered by lorry to the London factory from a 
Glasgow firm of charcoal manufacturers on July 13 and was the first batch to be processed in the factory for over six months. On arrival the charcoal was in granular form, up to $3 \mathrm{~mm}$. in diameter, and was contained in $\mathrm{I} \frac{1}{2}$-cwt. $(76.2 \mathrm{~kg}$.) second-hand jute sacks, many of which bore names indicating that they had originated in Pakistan or India. The patient's task was to carry these sacks of granular charcoal up a short stairway and empty thern into the hopper of a grinding machine; he then had to weigh out the ground, finely powdered charcoal into I-cwt. $(50.8 \mathrm{~kg}$.) quantities in paper sacks, as it was discharged from the machine. Because of the dusty nature of the work, micro-filter dust respirators were provided for the employees in the grinding room.

Charcoal and sacks from the London grinding factory were examined for $B$. anthracis. A single colony of $B$. anthracis grew from one of two samples of unground granular charcoal which were examined. Five samples of ground, powdered charcoal were examined with negative results. Examination of the second-hand sacks in which the charcoal arrived at the London factory resulted in the isolation of $B$. anthracis from four out of six sacks. Other sacks in the factory containing various materials other than charcoal were examined with negative results. The cellullose filter pad from the patient's respirator was examined and was free from $B$. anthracis.

\section{The Bone Charcoal}

For technical reasons, bone charcoal can be prepared only from 'desert-dried' bones; these are the bones of fallen animals, picked clean and exposed to sun and air for several years. Such bones are imported from India, Pakistan, and South America and carry a well-recognized anthrax risk; over the past I4 years there have been eight cases of cutaneous anthrax among the 20 employees at the bone charcoal factory in Glasgow. A bacteriological study of the raw bone had been conducted at that factory some months before the patient's death, and $B$. anthracis was isolated from 19 of 36 samples of raw bone. Later studies showed a similar high proportion of infected samples in the raw material.

In the manufacture of bone charcoal, raw bone is ground to a suitable size and carbonized by heating at a temperature of $1000^{\circ} \mathrm{C}$. for several hours and this process effectively sterilizes it. For transport to London the sterile charcoal was filled into secondhand sacks, vacuum-cleaned but unsterilized, and some had been used to import the raw bone. The use of sacks for the transport of bone charcoal has now been discontinued.

\section{Discussion}

Although the terminal phase of pulmonary anthrax is very rapid, the illness usually starts two to three days before death. Often, there are respiratory symptoms (Plotkin, Brachman, Utell, Bumford, and Atchison, 1960), but none was observed in the case reported here. The necropsy findings were unusual in that the massive haemorrhagic mediastinitis, which is often a feature of fatal pulmonary anthrax, was not found.

The most striking feature of this case was the development of pulmonary anthrax after apparent minimal exposure to anthrax spores. The source of infection was presumably the sacks in which the charcoal was delivered; the patient had handled about a hundred of them in the eight days before he was taken ill, and four of the six examined yielded a growth of $B$. anthracis.

Fatal pulmonary anthrax following minimal exposure to infection has been reported previously by Brachman and his colleagues (Brachman, Pagano, and Albrink, 196I); they described two cases in persons living or working near a tannery in which infected goat skins were processed.

Paradoxically, the infectivity of $B$. anthracis for man must normally be regarded as low. The evidence in support of this statement comes from a consideration of the amount of potentially infected raw material imported into this country and the rarity of human infection, even by the cutaneous route.

Dahlgren and his colleagues (Dahlgren, Buchanan, Decker, Freed, Phillips, and Brachman, 1960) found that, in the dustiest parts of a plant processing goat hair in the United States, the workers were inhaling between 600 and $I, 300$ anthrax spores during the working day and that between $25 \%$ and $50 \%$ of these spores were associated with particles smaller than five microns. Apparently these men suffered no ill effect, although pulmonary anthrax occurred in another factory with a similar level of air contamination. For monkeys the $\mathrm{LD}_{50}$ dose of anthrax spores inhaled as single spore particles is about 50,000 (Druett, Henderson, Packman, and Peacock, 1953), and this indicates the small chance of a single spore germinating and causing infection.

The illness in man is complicated by the development of partial immunity following prolonged exposure to anthrax-contaminated materials (Norman, Ray, Brachman, Plotkin, and Pagano, 1960). Such an immunity may account for the relative infrequency of anthrax infection among the employees of the firm manufacturing the bone charcoal. It seems, however, that the exposure of fully suscep- 
tible individuals to minimal doses of anthrax spores is not without risk.

We wish to thank Dr. S. A. Boyd, Deputy Medical Officer of Health, London Borough of Tower Hamlets, Dr. W. M. Brent, general practitioner, Dr. R. Owen, Medical Inspector of Factories, and Mr. L. Pinguey, Deputy Chief Public Health Inspector, London Borough of Newham, for their help in this investigation.

\section{REFERENCES}

Brachman, P. S., Pagano, J. S., and Albrink, W. S. (I961). Two cases of fatal inhalation anthrax, one associated with sarcoidosis. New Engl. F. Med., 265, 203-208.
Dahlgren, C. M., Buchanan, L. M., Decker, H. M., Freed, S. W., Phillips, C. R., and Brachman, P. S. (1960). Bacillus anthracis aerosols in goat hair processing mills. Amer. F. Hyg., 72, 24-31.

Druett, H. A., Henderson, D. W., Packman, L., and Peacock, S. (1953). Studies on respiratory infection. I. The influence of particle size on respiratory infection with anthrax spores. F. Hyg. (Lond.), 51, 359-37I.

Ministry of Labour (1959). Report of the Committee of Enquiry on Anthrax. H.M.S.O., London.

Norman, P. S., Ray, J. G., Brachman, P. S., Plotkin, S. A., and Pagano, J. S. (I960). Serologic testing for anthrax antibodies in workers in a goat hair processing mill. Amer. F. Hyg., 72, 32-37.

Plotkin, S. A., Brachman, P. S., Utell, M., Bumford, F. H., and Atchison, M. M. (1960). An epidemic of inhalation anthrax, the first in the twentieth century. Amer. F. Med., 29, 992-1001. 